\title{
Rolling, Partial and Full Annealing of 6061 Characterization of Microstructure, Tensile Strengths and Ductility
}

\author{
Wei Zhang1,2 \\ ${ }^{1}$ Mine Management Division, Department of Mining \& Mineral Resources, Chinalco China Copper Corporation Limited, Beijing, China \\ ${ }^{2}$ Department of Mining and Materials Engineering, McGill University, Montreal, QC, Canada \\ Email: zhang_wei@chalco.com.cn
}

How to cite this paper: Zhang, W. (2016) Rolling, Partial and Full Annealing of 6061 Characterization of Microstructure, Tensile Strengths and Ductility. Materials Sciences and Applications, 7, 453-464.

http://dx.doi.org/10.4236/msa.2016.79040

Received: June 13, 2016

Accepted: August 28, 2016

Published: September 1, 2016

Copyright $\odot 2016$ by author and Scientific Research Publishing Inc. This work is licensed under the Creative Commons Attribution International License (CC BY 4.0).

http://creativecommons.org/licenses/by/4.0/

\section{Abstract}

The scope of this research is to compare the grain morphology and hardness of aluminum alloy 6061 samples in three conditions: fully rolled (full hard), partially annealed (half hard), and fully annealed (soft). It is found that cold rolling produced elongated grains, parallel to the rolling direction, and the highest degree of grainelongation is found as a band in the center of the specimens. Shearing effects of cold rolling the buckled surface produced equiaxed grains near the rolling surfaces, and may have played a role in reducing the effect of string forming solutes near the said surfaces. Higher percent reduction performed in one stage of cold rolling produced a higher increase in tensile strength and a more significant decrease in ductility. Annealing produced the softest material.

\section{Keywords}

Cold Rolling, Annealing, Grain-Elongation, Tensile Strength, Ductility

\section{Introduction}

The $6 \mathrm{xxx}$ series aluminum alloys are heat-treatable wrought alloys with magnesium and silicon as the primary alloying elements. Alloys of this series are characterized by good formability, weldability, machinability, and corrosion resistance, and moderately high strength [1]-[3]. The basis for their strength is the formation of magnesium silicide $\left(\mathrm{Mg}_{2} \mathrm{Si}\right)$, which forms if the elements are present in the proportions of $1.73: 1$ ( $\mathrm{Mg}$ to $\mathrm{Si}$ ) [4]. 6xxx series alloys are often used for structural applications since they have a medium strength and good weatherability. 
Despite the fact that the common strengthening mechanism employed for this alloy is age hardening, the scope of this project was to compare the grain morphology and hardness of samples in three conditions: fully rolled (full hard), partially annealed (half hard), and fully annealed (soft). The samples were prepared by cold rolling and appropriate annealing heat treatments.

\subsection{Theoretical Background}

The strength of aluminium can be increased by the following methods: solute hardening, second phase hardening, grain size hardening or strain hardening. The strengthening mechanism of importance in this case is the latter. Strain Hardening, also known as Cold Working strengthens the material by increasing the dislocation density in the crystal lattice. Beyond a critical dislocation density (Figure 1), the strength of the material will increase.

As dislocation density grows, the dislocations become tangled with each other effectively stopping slip from occurring. There is also dislocation pileup that occurs when dislocations that are able to move get caught in a tangle and are no longer able to move through the crystal lattice. These dislocation pileups increase the yield strength of the material, but at the expense of its ductility [6] [7]. Figure 2 demonstrates this effect. As the percent cold work increases, the yield strength increases, and the ductility drops significantly.

The effects of Strain Hardening can be removed by annealing [9] [10]. Annealing provides the energy required for the material to reverse the increase in dislocation density such that it will return to its previous state. There are three steps to the annealing process: recovery, recrystallization and grain growth. The recovery stage is characterized

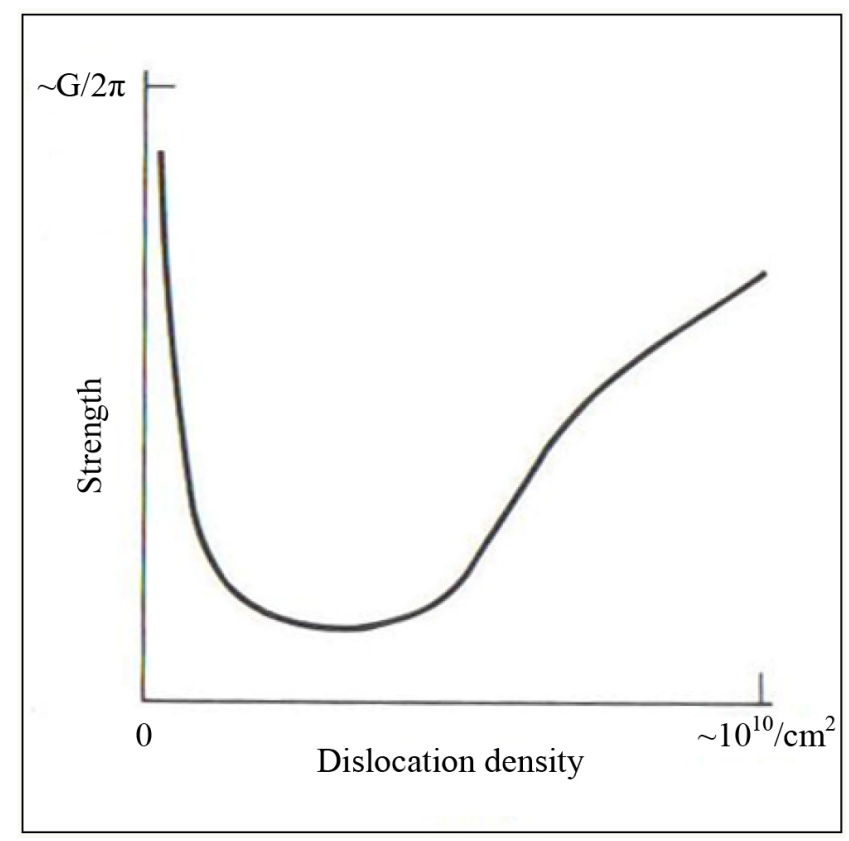

Figure 1. Strength as a function of dislocation density [5]. 


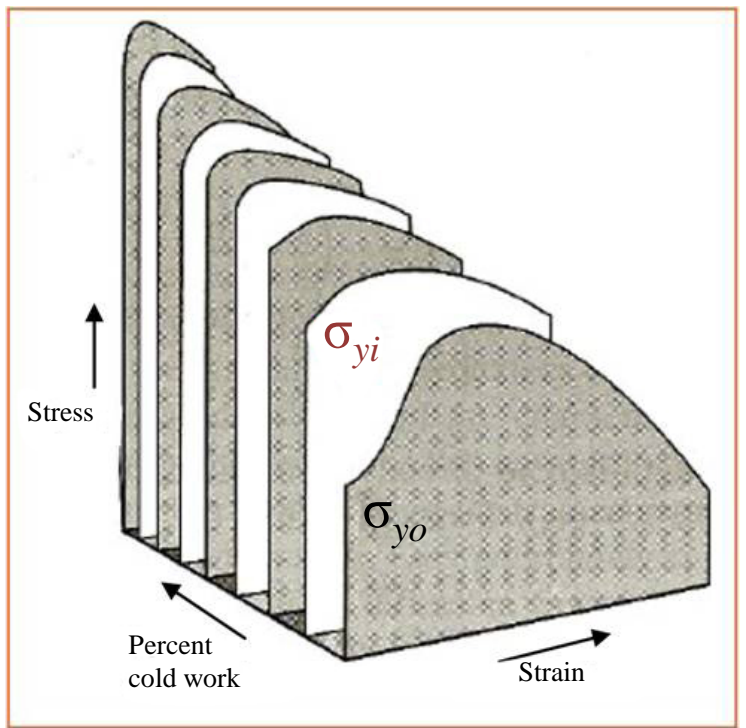

Figure 2. Increasing \%CW increases stress ( $\sigma$ represents the strain) [8].

by the rearrangement of the crystal lattice and release of the stored energy. Recrystallization is characterized by the nucleation of new, dislocation free grains throughout the structure, and finally, grain growth occurs, these new dislocation-free grains will grow in size. The change in macrostructure is noticeable between these stages, and these changes are also noticeable in the strength of the material.

\subsection{Experimental Procedure}

\section{Coupon Preparation}

The details of each step are included in the sub-sections below. Temper designations are discussed in Section 2.2.1. Three coupons were prepared by the following:

Coupon 1: fully annealed, fully rolled (to lab. capabilities ${ }^{1}$ )

Coupon 2: fully annealed, fully rolled (to lab. capabilities), fully annealed

Coupon 3: fully annealed, fully rolled (to lab. capabilities), fully annealed, rolled to half of fully roll.

\section{Annealing}

Three $2 \times 4$ inch coupons were cut from the original plate of aluminum AA6061. These samples were placed in the SPX Blue M Electric Oven (Mechanical Convection) with a starting temperature of $415^{\circ} \mathrm{C}$ for 3 hours. The furnace was checked after 3 hours and the temperature was reduced by $30^{\circ} \mathrm{C}$ every hour until the furnace reached a temperature of $260^{\circ} \mathrm{C}$. Once this temperature was achieved the furnace was shut off. The samples were each removed shortly after and placed on refractory bricks to cool to room temperature.

A safety shield to protect the face, a long sleeved safety jacket and insulated gloves were used to ensure safe removal of the sample from the oven. Tongs were used to han-

${ }^{1}$ To avoid severe buckling. 
dle the aluminum.

Rolling

The Stanat Rolling Mill was first switched on and the safety shut off guards were verified. Every effort was made to ensure safe operation of the rolling machine.

Before rolling, each coupon was engraved with a sample number and a rolling direction. The original thickness of each sample averaged $12.77 \mathrm{~mm}$. To obtain the required full hard structure a $60 \%-70 \%$ reduction in the thickness was estimated to be necessary.

Due to the buckling that occurred during the rolling procedure it was not possible to achieve the desired range. The $\% \mathrm{CW}$ obtained was $49 \%$ with a reduction in thickness to $6.42 \mathrm{~mm}$.

\section{Re-Annealing}

Two of the coupons were then re-annealed. A similar process was used with the furnace except the second time P. Vermette created a program for the SPX Oven controller to automate the reduction in temperature at specified intervals.

\section{Second Rolling}

Sample 3 was rolled again to a final thickness of $4.8 \mathrm{~mm}$ which represents about $25 \% \mathrm{CW}$. This sample represented the partial annealed structure.

\subsection{Hardness Measurements}

The 3 samples were tested for their hardness using the Rockwell hardness testing. The Rockwell $\mathrm{H}$ scale (60 Kg, 1/8" ball) was used since it is the most suitable scale for the material used for this project, as shown in Figure 3.

The sample was placed on the anvil.

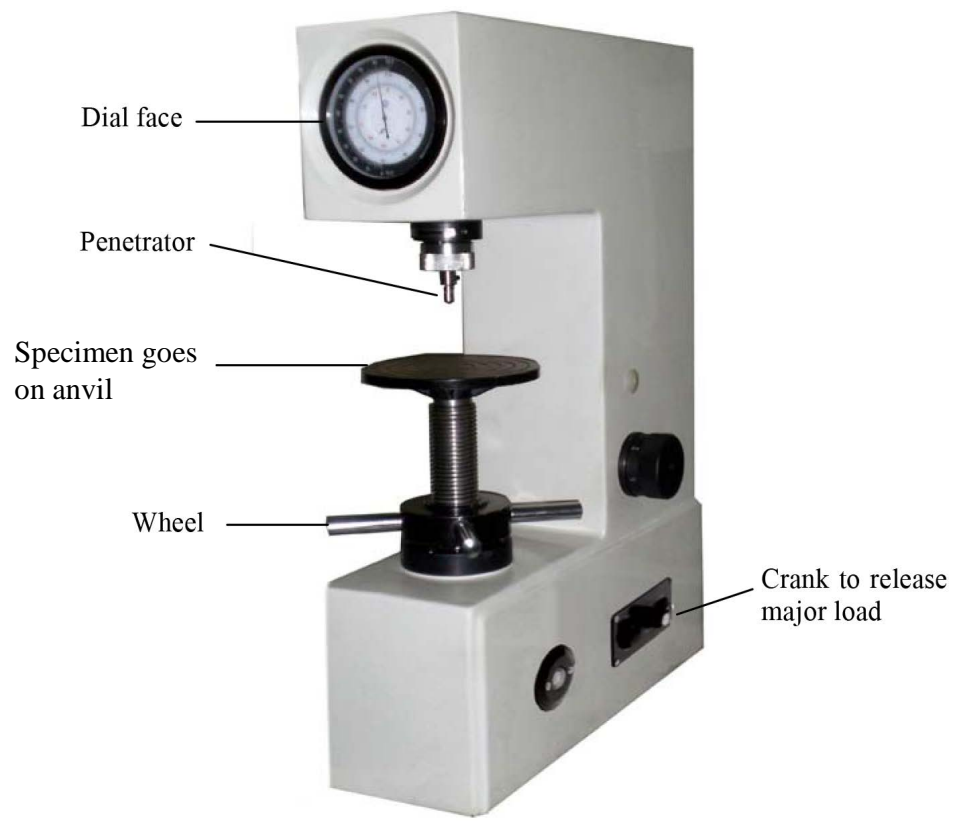

Figure 3. Major components of a Rockwell hardness tester [4]. 
The penetrator was slowly approached onto the sample's surface until the small pointer reaches the black dot (Figure 3). This was necessary to remove any residual stress in the specimen before the major load is applied.

The scale was adjusted to the set point. There were 2 scales on the machine; coloured red and black respectively. For the Rockwell $\mathrm{H}$ scale, as written on the machine itself, the scale in red was used.

The crank was then released to apply the major load.

When the crank was completely stabilized, it was pulled back (counter clockwise) and the reading on the scale was taken.

Six readings were taken for each of the three samples and an average value was calculated.

\subsection{Metallography and Macro-Etching}

Small samples we cut from the coupons, about 1 inch in length. The area to be investigated was that perpendicular to the top surface, parallel to the rolling direction. The samples were then grinded and polished as per the following:

The samples were grinded using $\mathrm{SiC}$ papers, using 400, 600, 800, then 1200 grit.

The samples were then polished with 5 and 10 micron alumina, and finished on a cloth with colloidal silica.

In between steps the samples were immersed in the ultrasonic bath to remove as loose particles.

The samples were rinsed with water, then dried with ethanol.

Once the samples had been adequately polished, i.e. mirror-like finish obtained, the samples were etched to reveal the grain boundaries. The etchant used was Poulton's reagent, it contained the following: $12 \mathrm{~mL}$ of $\mathrm{HCl}, 6 \mathrm{~mL} \mathrm{HNO}_{3}, 1 \mathrm{~mL} \mathrm{HF}$ and $1 \mathrm{~mL} \mathrm{H}_{2} \mathrm{O}$. The time needed to etch the samples is important. For the three samples, it was found that 30 seconds was sufficient. The macrostructure was then visible to the naked-eye and images were taking using SZ-CTV Olympus stereo microscope.

\section{Results \& Discussion}

\subsection{Macrostructural Characterization}

Figures 4-6 are representing the micrographs of the three samples cut from coupons 1, 2 and 3, respectively. As previously mentioned, the cross-section perpendicular to the top (rolled) surface, parallel to the rolling direction was etched. The micrographs below include the entire height of each sample to show the grain morphology distribution from rolled surface to rolled surface.

For the fully rolled sample (coupon 1, Figure 4), it is evident that the grains are not entirely elongated. The grains close to both rolled surfaces show finer, equiaxed grains. This is believed to have incurred during the rolling procedure due to buckling of the sample. Due to buckling, the surfaces were not flat, thus the loading from the rolling mill was not pure compression - there was also shearing of the surface.

In Figure 5, the fully annealed sample, most of the grains are small and equiaxed, 


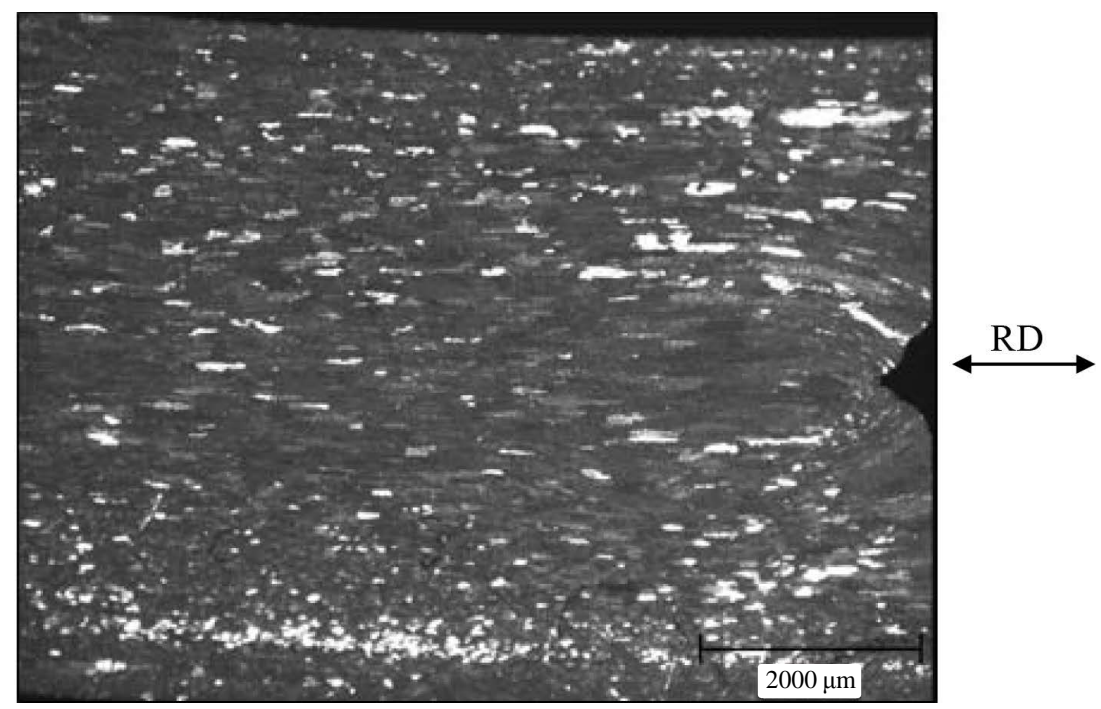

Figure 4. Macrograph of sample taken from coupon 1, "fully" rolled (AA6061 H16). As etched with Poulton's reagent.

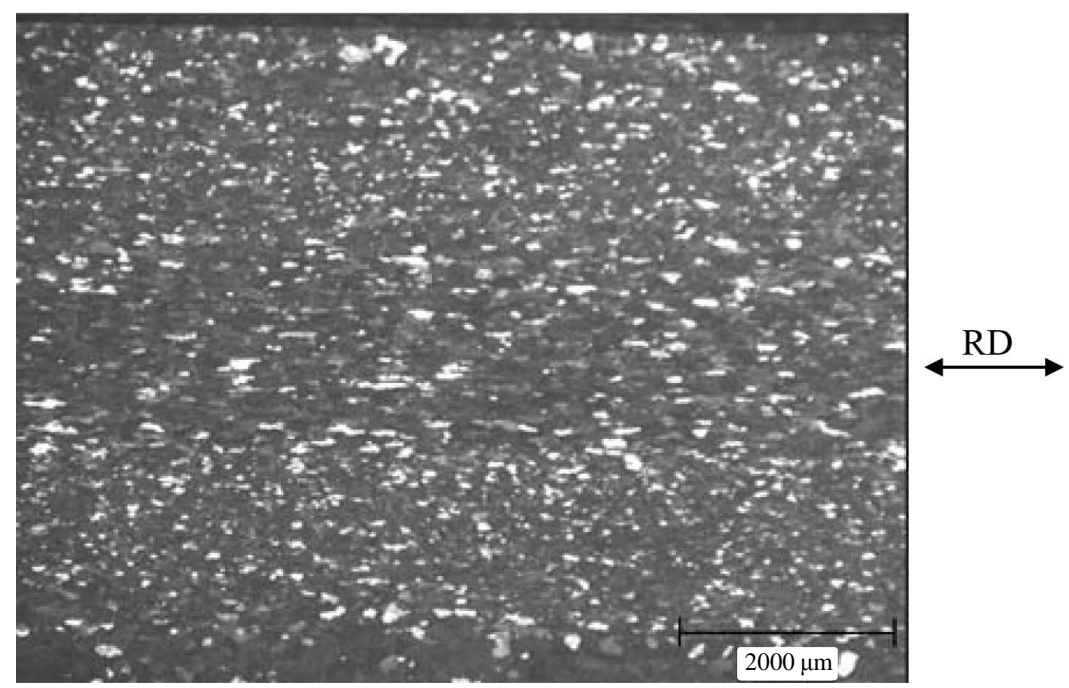

Figure 5. Macrograph of sample taken from coupon 2, fully annealed (AA606-O). As etched with Poulton's reagent.

which shows that the annealing procedure was successful. The grains remained small, which suggests that grain growth was kept to a minimum. It is interesting to note, however, that there is a band in the center of the sample of elongated grains. There is the possibility of strings formation due to elements such as $\mathrm{Cr}, \mathrm{Mn}$, or $\mathrm{Zr}$. This is possible since $\mathrm{Cr}$ and $\mathrm{Mn}$ are present in AA6061 (0.15 Mn, $0.04-0.35 \mathrm{Cr})$; however, it is not clear why the strings are only present in the center. One option is segregation of solute atoms in the ingot, or the second is the effect of string forming elements was overcome by shear near sample surface.

Figure 6, which is the partially annealed sample shows the highest degree of elongation of the three coupons. This was to be expected since the sample was rolled with the 


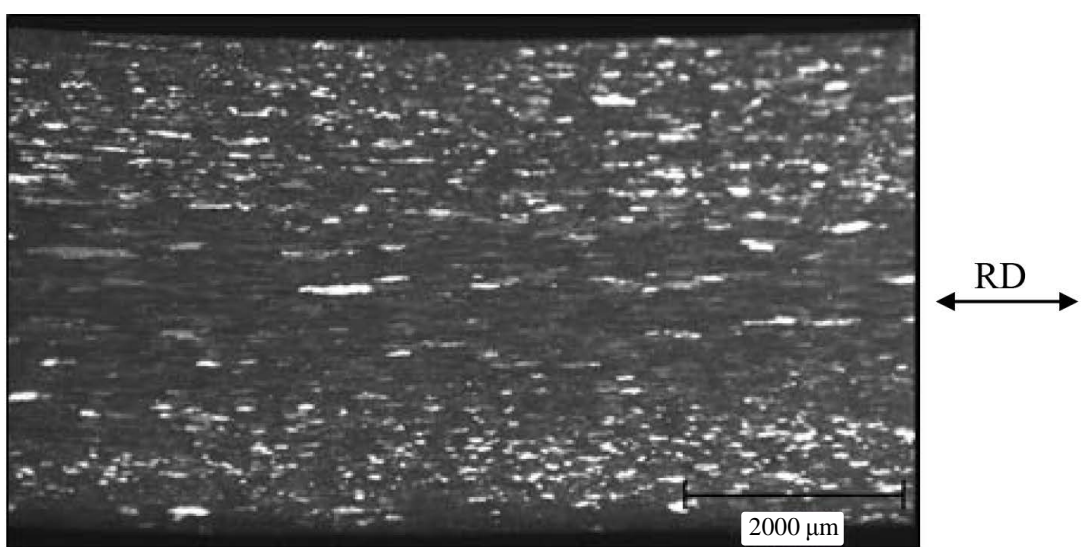

Figure 6. Macrograph of sample taken from coupon 3, partially annealed rolled (AA6061 H13). As etched with Poulton's reagent.

sample force from the roll as the coupon 1 and in the same soft state (annealed); however, the thickness was smaller, thus the pressure was higher. Again, the sample showed the most elongated grains in the center. The reason for this was likely a combination of shearing effects at the surface, and possibly string formation.

\subsection{Tensile Properties}

Table 1 shows the hardness readings taken using the Rockwell Hardness Tester. Six readings were taken for each sample and an average was calculated from those numbers. The stock sample was the sample that was received from P. Vermette and fully annealed before any cold rolling was done.

\subsubsection{Temper Designation}

It was known that coupons 1 and 3 were under the designation of H1X since they were strain-hardened (via cold-rolling) only. However, it was necessary to calculate the extent of cold-working by computing the percent reduction to determine the second number in the designation. Percent reduction is defined as follow:

$$
R=\frac{t_{i}-t_{f}}{t_{i}} \times 100
$$

where $t$ is the thickness of the sample, and subscripts $i$ and $f$ denoting initial and final, respectively. The values calculated for coupons 1 and 3 are included in Table 2.

Therefore, the temper designation for coupon 1 is H16 (slightly harder than $1 / 2$ hard) and for coupon 3 is H13. Temper designation for coupon 2 is O temper since it was fully annealed.

\subsubsection{Tensile Strength}

Two ways were used to compute the tensile strength of the samples: through percent reduction and through hardness. Calculating the tensile strength through reduction involves the following formula:

$$
T=T_{o}(1+0.9 R)
$$


Table 1. Hardness readings (in Rockwell H Scale) for all samples.

\begin{tabular}{|c|c|c|c|}
\hline \multirow{2}{*}{ Sample } & \multicolumn{3}{|c|}{ Rockwell Hardness [HRH] } \\
\hline & Individual Reading & Average & Standard Deviation \\
\hline \multirow{6}{*}{ AA6061 Stock } & 60.5 & \multirow{6}{*}{60} & \multirow{6}{*}{0.3} \\
\hline & 60.0 & & \\
\hline & 59.5 & & \\
\hline & 60.0 & & \\
\hline & 60.0 & & \\
\hline & 60.0 & & \\
\hline \multirow{6}{*}{ Coupon 1} & 92.5 & \multirow{6}{*}{93.9} & \multirow{6}{*}{0.9} \\
\hline & 94.0 & & \\
\hline & 95.0 & & \\
\hline & 94.0 & & \\
\hline & 94.5 & & \\
\hline & 93.5 & & \\
\hline \multirow{6}{*}{ Coupon 2} & 56.0 & \multirow{6}{*}{57.9} & \multirow{6}{*}{1.2} \\
\hline & 57.0 & & \\
\hline & 59.0 & & \\
\hline & 58.5 & & \\
\hline & 59.0 & & \\
\hline & 58.0 & & \\
\hline \multirow{6}{*}{ Coupon 3} & 87.0 & \multirow{6}{*}{86.5} & \multirow{6}{*}{0.8} \\
\hline & 87.0 & & \\
\hline & 85.0 & & \\
\hline & 87.0 & & \\
\hline & 87.0 & & \\
\hline & 86.0 & & \\
\hline
\end{tabular}

Table 2. Computation of tensile strength using percent reduction.

\begin{tabular}{cccc}
\hline Sample & Temper & Reduction [\%] & Tensile Strength [MPa] \\
\hline Coupon 1 & H14 & 49.6 & 179.2 \\
Coupon 3 & H12 & 25.7 & 152.2 \\
\hline
\end{tabular}

where $T=$ tensile strength of sample in $\mathrm{MPa}, T_{o}=$ tensile strength in MPa of fully annealed material, and $R=$ reduction expressed as a decimal. Using Equation (2) with $T_{o}$ $=124 \mathrm{MPa}$ and $R$ values obtained, the tensile strengths for samples 1 and 3 were calculated. The following table shows the calculated numbers:

The tensile strengths were also estimated using the hardness measurements with the following equation. In this equation, $T$ is the tensile strength of sample in pounds per square inch, and $B H N$ is the Standard Brinell hardness.

$$
T=575 \times B H N
$$

It was necessary to convert the Rockwell $\mathrm{H}$ Scale hardness measurements to Standard Brinell hardness using data from literature [3]. Table 3 shows numbers obtained 
Table 3. Computation of tensile strength using hardness readings.

\begin{tabular}{ccccc}
\hline Sample & Rockwell H Scale & Brinell Hardness & Tensile Strength (ksi) & Tensile Strength (MPa) \\
\hline Stock & 60.0 & 19.1 & 10.9 & 75.5 \\
$6061 \mathrm{H} 16$ & 93.9 & 55.5 & 31.9 & 219.8 \\
$6061 \mathrm{O}$ & 57.9 & 17.8 & 10.3 & 70.7 \\
$6061 \mathrm{H} 13$ & 86.5 & 43.9 & 25.2 & 174.0 \\
\hline
\end{tabular}

throughout the conversion and calculations:

Figure 7 shows the graph of conversion from Rockwell $\mathrm{H}$ Scale (HRH) to Brinell Hardness. For readings below $83 \mathrm{HRH}$, an extrapolation was done using the Excel trend line function. This gave a correlation coefficient of 0.9934 , which is a good fit.

For sample 2, tensile strength could only be determined through hardness since there was no effect of cold working. The tensile strength value was compared with those from the literature [4] for 6061-O Aluminum and those for the stock sample, as shown in Table 4. They were all in close agreement with one another. The stock sample was the sample that was received from $\mathrm{P}$. Vermette and fully annealed before any cold rolling was done.

The tensile strength values computed through reduction and through hardness readings can be summarized into the Table 5 . The percent error was calculated based on the formula:

$$
\% \text { Error }=\frac{T S_{\text {Reduction }}-T S_{\text {Hardness }}}{T S_{\text {Reduction }}} \times 100
$$

The percent error was calculated based on the assumption that the tensile strength estimation from reduction is a theoretical value while the tensile strength estimation from hardness is an experimental value. The sources of error largely stemmed from:

The Rockwell Hardness to Brinell Hardness conversion. Some hardness values were out of the literature range and had to be estimated through extrapolation.

The samples used for hardness were not entirely flat due to the cold-rolling. This might have affected the Rockwell Hardness readings since Rockwell tests require flat surfaces to achieve high accuracy.

Although the tensile strengths estimations were not extremely accurate numbers, their values can be compared relatively. Coupon 1 (H16 temper) had the highest tensile strength followed by coupon 3 (H13 temper). This is in coherence with theory since sample 1 has the highest amount of cold-rolling followed by sample 3 . The fully annealed sample have the lowest tensile strength, as expected since annealed is the softest state.

\subsubsection{Ductility}

Another property to be taken into consideration is the ductility of the samples. Since ductility is directly related to the percent elongation of the sample, the following formula was used for the computation of percent elongation of the cold-worked samples, where $e_{o}=$ elongation of the annealed material $=25 \%[4], \mathrm{R}=$ reduction expressed as a decimal: 


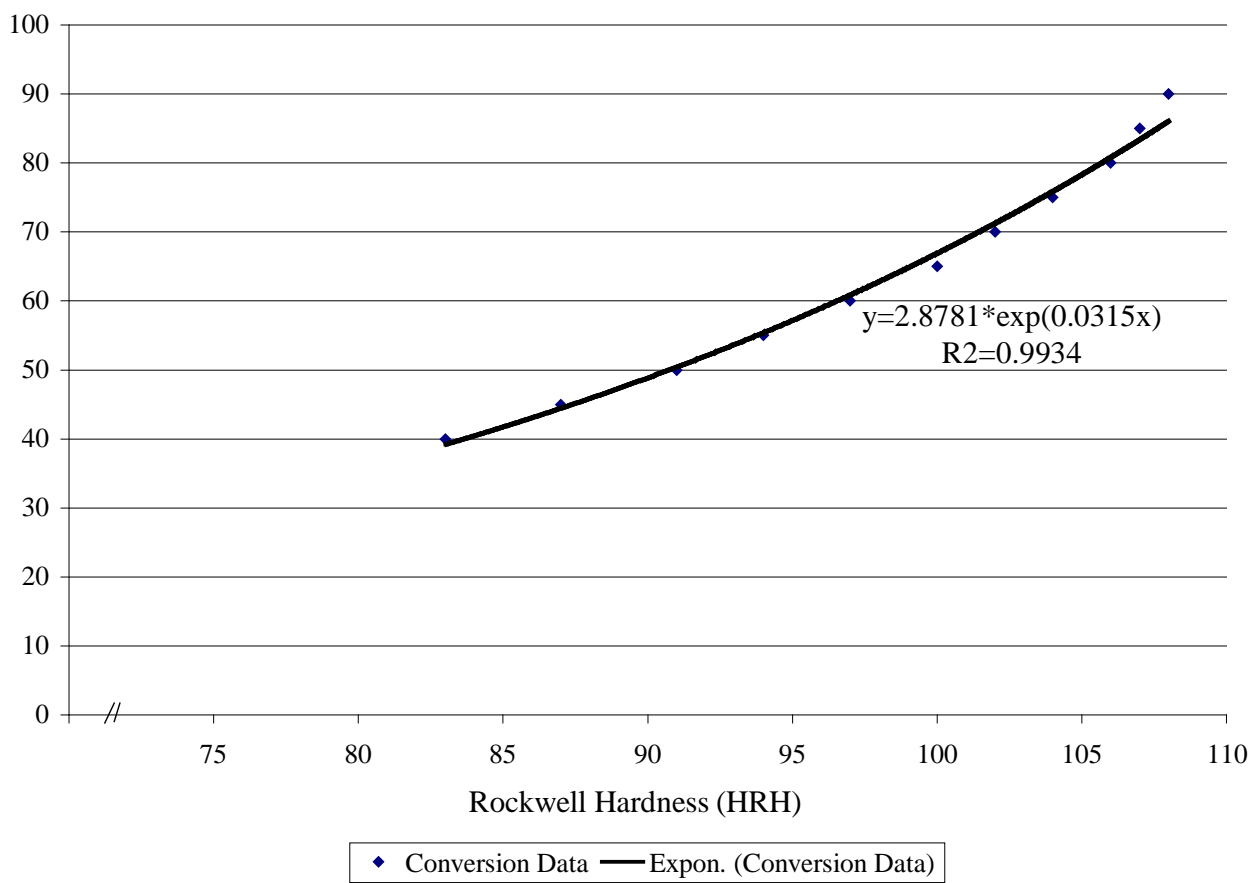

Figure 7. Hardness conversion from Rockwell H Scale to Standard Brinell Hardness. The graph was constructed based on numbers from literature.

Table 4. Comparison of tensile strengths of 6061-O from literature and from experiment (Sample 2 and Stock).

\begin{tabular}{ccc}
\hline Source & Tensile Strength $(\mathrm{MPa})$ & Hardness $(\mathrm{HRH})$ \\
\hline Literature & $75.5-124$ & $60-75$ \\
Coupon 2 & 70.7 & 57.9 \\
Stock AA6061 provided & 75.5 & 60 \\
\hline
\end{tabular}

Table 5. Comparison of tensile strengths.

\begin{tabular}{cccc}
\hline \multirow{2}{*}{ Sample } & \multicolumn{3}{c}{ Tensile Strength (MPa) } \\
\cline { 2 - 4 } & Reduction & Hardness & \% Error \\
\hline $6061 \mathrm{H} 14$ & 179.2 & 219.8 & 22.7 \\
$6061 \mathrm{H} 12$ & 152.2 & 174 & 14.4 \\
\hline & & \\
& & & \\
& & & \\
& &
\end{tabular}

As can be seen in Table 6, the higher the degree of cold-rolling, the lower the percent elongation (lower the ductility). As such, one can see the following relationship from the experimental results: more strain hardening, the harder the material (higher the tensile strength), and the less ductile the material (lower percent elongation).

\section{Conclusions}

Cold rolling produced elongated grains, parallel to the rolling direction. 
Table 6. Percent elongation of cold-worked samples.

\begin{tabular}{ccc}
\hline Sample & Temper & Elongation (\%) \\
\hline Coupon 1 & $6061 \mathrm{H} 16$ & 10.7 \\
Coupon 3 & $6061 \mathrm{H} 13$ & 13.3
\end{tabular}

The highest degree of grain-elongation was found in the center of the specimens.

Shearing effects of cold rolling the buckled surface produced equiaxed grains near the rolling surfaces, and may have played a role in reducing the effect of string forming solutes near the said surfaces.

The higher percent reduction performed in one step of cold rolling produced a higher increase in tensile strength and a more significant decrease in ductility; this corresponds to theory.

There is a noticeable difference between the tensile strength estimation through percent reduction and tensile strength estimation through hardness. The difference largely stemmed from errors surfacing from hardness unit conversion from Rockwell to Brinell and the condition of the samples used for hardness testing (they were not flat).

\section{Acknowledgements}

The author would like to acknowledge Pierre Vermette and Marwan Azzi for the laboratory support.

\section{References}

[1] Emel, T., Jerry, E.G. and John, C.L. (2010) Dissimilar Friction Welding of 6061-T6 Aluminum and AISI 1019 Steel: Properties and Microstructural Characterization. Materials and Design, 31, 2305-2311. http://dx.doi.org/10.1016/j.matdes.2009.12.010

[2] Bang, H.S., Bang, H.S., Jeon, G.H., et al. (2012) Gas Tungsten Arc Welding Assisted Hybrid Friction Stir Welding of Dissimilar Materials Al6061-T6 Aluminum Alloy and STS304 Stainless Steel. Materials and Design, 37, 48-55. http://dx.doi.org/10.1016/j.matdes.2011.12.018

[3] Moreira, P., Figue, M. and Castro, P. (2007) Fatigue Behavior of FSW and MIG Weldments for two Aluminum Alloys. Theoretical and Applied Fracture Mechanics, 48, 169-177. http://dx.doi.org/10.1016/j.tafmec.2007.06.001

[4] Wu, Y., Kim, G. and Russell, A. (2012) Effects of Mechanical Alloying on an AL6061-CNT Composite Fabricated by Semi-Solid Power Processing. Materials Science and Engineering $A, 48,164-172$.

[5] Zhang, Z. and Zhang, H.W. (2009) Numerical Studies on Controlling of Process Parameters in Friction Stir Welding. Journal of Materials Processing Technology, 209, 241-270. http://dx.doi.org/10.1016/j.jmatprotec.2008.01.044

[6] Qi, Y.L., Deng, J., Hong, Q., et al. (2010) Electron Beam Welding Laser Beam Welding and Gas Tungsten Arc Welding of Titanium Sheet. Materials Science and Engineering, A280, $177-181$

[7] Jonghyun, K. and Kawamura, Y. (2007) Electron Beam Welding of the Dissimilar Zr Based Bulk Metallic Glass and Ti Metal. Scripta Materialia, 56, 709-712.

http://dx.doi.org/10.1016/j.scriptamat.2006.12.046 
[8] Arivazhagan, N., Surendra, S. and Satva, P. (2011) Investigation on AISI 304 Austenitic Stainless Steel to AISI 4140 Alloy Steel Dissimilar Joints by Gas Tungsten Arc Electron Beam and Friction Welding. Materials and Design, 32, 3036-3050.

http://dx.doi.org/10.1016/j.matdes.2011.01.037

[9] Magnabosco, I., Ferro, P. and Bonollo, F. (2006) An Investigation of Fusion Zone Microstructures in Electron Beam Welding of Copper-Stainless Steel. Materials Science and Engineering A, 424, 163-173. http://dx.doi.org/10.1016/j.msea.2006.03.096

[10] Wang, S.-H. and Wang, J.-Y. (2008) Study on the Pore of Vacuum Electron Beam Welding 2Al12 Aluminum Alloy. Machinery Design \& Manufacture, 211, 143-145.

Submit or recommend next manuscript to SCIRP and we will provide best service for you:

Accepting pre-submission inquiries through Email, Facebook, LinkedIn, Twitter, etc. A wide selection of journals (inclusive of 9 subjects, more than 200 journals)

Providing 24-hour high-quality service

User-friendly online submission system

Fair and swift peer-review system

Efficient typesetting and proofreading procedure

Display of the result of downloads and visits, as well as the number of cited articles

Maximum dissemination of your research work

Submit your manuscript at: http://papersubmission.scirp.org/ 